\title{
X. Cordierithornfels aus dem Kontakthofe von Rican, s. ö. von Prag.
}

\author{
Von A. Pelikan (Prag).
}

Die nachstehenden Bemerkungen sollen nur eine Ergänzung zu der ausführlichen Beschreibung des Ricaner Kontakthofes darstellen, die von Katzer teils im Jahrbuche d. g. R. 1888, teils in den Verhandlungen (Juli 1904) publiziert worden ist. Es handelt sich um den Cordierithornfels, dessen von Katzer besonders in der letztgenannten Arbeit mehrfach Erwähnung getan wird, ohne daß aber eine ansführlichere Beschreibung gegeben warde. Da ich nun gelegentlich einer Exkursion, die ich mit meinen Hörern im Frühjahre 1904 in dieses wirklich hochinteressante Gebiet unternommen habe, ein Hornfelsvorkommen auffand, das von Katzer nicht erwähnt wird, und dasselbe etwas genauer studierte, so dürfte es nicht unangebracht sein, bier in Kürze darïber za berichten, um so mehr als dieses Vorkommen seiner Beschaffenheit nach mit keinem der von Katzer erwähnten völlig übereinznstimmen scheint. ${ }^{1}$ )

An der Straße von Gr.-Tehov nach Světitz liegen zwei große Blöcke, die zwei Abarten von Cordierithornfels repräsentieren. Der eine $A$ besitzt bei rein massiger Ausbildung eine deutlich porphyrische Struktur. Die Grundmasse ist außerordentlich fein krystallinisch, dunkelgraa, uneben brechend und infolge massenhaft vorhandener Glimmerschiippchen silbrig schimmernd. In dieses Grundaggregat

1) Eine vorlänfige Notiz warde bereits im Anhange an einen Exkursionsbericht in den "Mitteil. des akad. Vereines dentscher Naturhistoriker in Prag", Juni 1904 veröffentlicht. 
sind zahlreiche, fast schwarze Cordierite, in Form und Grōße Getreidekörnern ähnlich, eingebettet. Schärfer ausgebildete Krystalle finden sich verhältnismäßig selten und liefern dann mehr oder minder gut umgrenzte Sechsecks-Querschnitte. Die meisten Individuen sind aber gerundet und besitzen infolgedessen die Form gedrungener Spindeln. Abgesehen von der Größe, erinnern sie durch ihre dunkle Farbe und den ebenen, schwach fettglänzenden Bruch an manche als "harter Fahlunit" bekannte Vorkommen des Cordierits." )

Bei dem zweiten Blocke $B$ ist das Korn merkbar gröber als bei dem ersten, der krystalline Charakter der Grundmasse also deutlicher, der Bruch splittrig und die dunkle Farbe mit einem deutlichen Stich ins Branne versehen, der besonders auffallend an den halb losgelösten Splitterchen des Bruches hervortritt. Dabei treten aber hier die Cordierit-Idioblasten stark zurück und das Gestein läßt auf der verwitterten Oberfläche Merkmale einer ehemaligen Schichtung erkennen. Die einzelnen Lagen baben Dicken von $1 \mathrm{~cm}$ bis etwa $10 \mathrm{~cm}$, wie man sie bei sehr feinkörnigen schiefrigen Sandsteinen so häufig antrifft.

Das Grundaggregat der Modifikation A besteht hauptsächlich ans Quarzkörnern, denen auch Feldspat beigemengt ist. Ein diesbezüglicher Ätz- und Färbeversuch bat ein überzeugendes Resultat allerdings nicht geliefert, doch gibt die Analyse begründeten Anlaß3, Orthoklas im Grundaggregate zu vermuten. Deutlich erkennbar sind dagegen die sehr spärlich erscheinenden Plagioklase, von denen es mir aber nicht ganz sicher erscheint, ob sie nicht aus dem friiheren Mineralbestande berübergenommen worden sind. Dem Grundaggregate regellos eingestreut sind Biotitschüppchen (max. $0.5 \mathrm{~mm}$ ), an denen die unvollkommene Raumerfullung auffällt; sie erscheinen siebartig durchlöchert, umschließen in der Regel Quarzkörner des Grundlaggregates und beherbergen als Einschlüsse Zirkonsäulchen, die von pleochroitischen Höfen umschlossen werden. Auch der Muscovit gebört nicht gerade 7.0 den seltenen Gemengteilen, aber seine Verteilung im Gesteine ist eine wesentlich andere als beim Biotit: er ordnet sich meist in Zügen an, die in der Lmgebung der Cordierite $\mathrm{zu}$ finden sind.

1) Gareiss, l'ber Psendomorphosen nach Cordierit. Tschermaks Mineral. a. petrogr. Mitt., XX, pag. 22. 
Als Andalusit sind wohl jene nicht sehr zahlreichen, unregelmäßig gelappten und noch weit stärker, als es beim Biotit der Fall ist, lückenhaft ausgebildeten Individuen zu betrachten, die bei hoher Lichtbrechung durch geringe Doppelbrechung sich auszeichnen. Die Anslöschung geht parallel den Spaltrissen und die ganze Art des Auftretens ähnelt durchaus jener des Andalusits in den Kontaktprodukten der Schiefer von Barr-Andlau.

Ferner ist ein, offenbar dem Pennin sebr nahestehendes Mineral vorhanden, das unregelnäßig begrenzte Lamellen bildet, die blaßgrün gefärbt sind und ganz schwachen Pleochroismus besitzen. Der Brechungsexponent ist etwas höher als bei Quarz, die Doppelbrechung schwach bis herab an die Grenze der Wahrnehmbarkeit.

Ganz vereinzelt trifft man Säulchen von Turmalin.

Der Apatit, dessen Vorhandensein durch die Analyse angezeigt wird, ist nur selten gut zu erkennen, er verbirgt sich unter den zahlreichen winzigen Säulchen und Körnchen, deren Natur auf optischem Wege nicht bestimnt werden kann.

Von Erzen sind vorbanden: Pyrit and Magnetit; ersterer unregelmäßige Körner bildend und an seiner Farbe im auffallenden Lichte leicht zu erkennen, letzterer in unregelmäßigen Körnern, zuweilen aber auch in quadratischen und hexagonalen Durchschnitten erscheinend.

Was endlich das mikroskopische Bild des Cordierit anlangt, so erscheint derselbe in prachtvollen Durchdringangsdrillingen, die den schönsten derartigen Bildungen in nichts nachstehen.

Die Modifikation B enthält im wesentlichen wohl die gleichen Gemengteile, jedoch in anderen Mengenverhältnissen. Der Cordierit tritt zurück, seine Durchschnitte zeigen die Drillingsbildung weniger deutlich und die Körner des Grundaggregates sind groß genug, um im Dünnschliffe stellenweise recht deutliche Pflasterstruktur zu entwickeln.

Da nur von der Modifikation A ein genügend großes Handstück zur Verfugung stand, so konnten auch nur von dieser Analysen ausgefïhrt werden, deren Ergebnisse im nachstehenden mitgeteilt werden. Die Zahlen I sind die Mittelwerte dreier gut stimmenden Analysen, von denen zwei durch Herrn Stud. phil. H. v. Lendenfeld, eine durch den Autor ausgeführt wurden. 


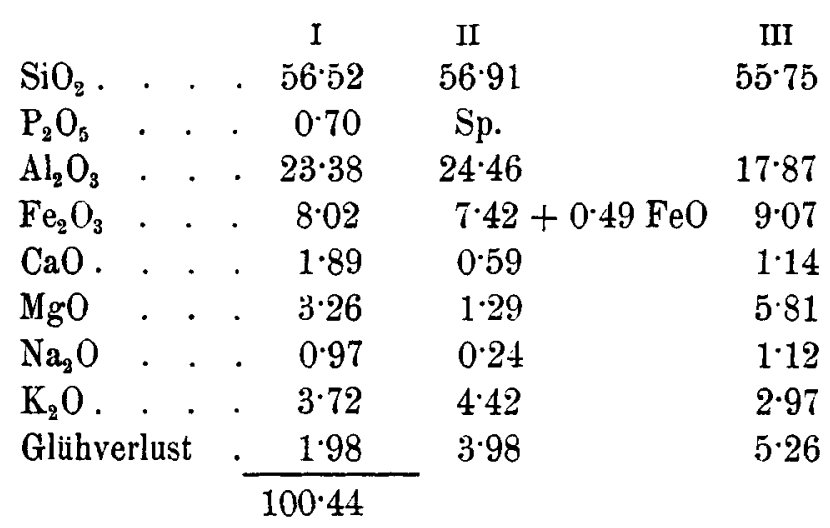

Unter II steht eine Analyse des sogenannten Burgsandsteines von Bondersbach bei Zirndorf, unfern Nürnberg nach Rosenbusch, Elemente, 2. Aufl., pag. 406, Analyse 20. Sie läßt unzweideutig erkennen, daß unser Hornfels ganz gut aus einem ähnlichen Gesteine entstanden sein kann. Von einem anderen Vorkommen aus dem Ricaner Kontakthofe, einem „körnigen, quarzreichen Gesteine, das reich ist an blauviolettem Cordierit" (Verhandl. R. A. 1904, 234) meint Katzer, es bätte das Gepräge „hochmetamorphosierter Grauwackensandsteine ${ }^{\text {", }}$ eine Vermutung deren Zulässigkeit durch unsere Analyse jedenfalls gestiitzt wird. Andrerseits darf aber doch nicht iibersehen werden, daß die durch die Analyse dargestellte Zusammensetzung ebenso gut, vielleicht sogar noch besser auf einen Tonschiefer bezogen werden kann, wie die unter III angeführte Analyse eines Tonschiefers von Danville zeigt. (Nach Rosenbusch, Elemente, pag. $442, \mathrm{Nr}$. 16.) Gegen die Annahme eines typischen Tonschiefers spricht wohl die Dieke der Lagen im Blocke B und so mag denn als das wahrscheinliche Muttergestein unseres Hornfelses ein dem Tonschiefer nahestebender, dünnspaltiger Sandstein angenommen werden. Zufällig steben auch alle Zablen der Analyse I (ausgenommen jene für $\mathrm{CaO}$ and den Gliihverlust) zwischen jenen von II und III. Die urspriunglich in Aussicht genommene Ausdehnung der Untersuchung auf mitvorkommende Gesteine mußte aufgegeben werden, da keiner der Studierenden die für chemische Analysen notwendige Zeit aufzuwenden vermag. Vielleicht kann die Sache später einmal in Angriff genommen werden.

$$
\text { Prag, Ostern } 1905 .
$$

